\title{
INFLUENCE OF ACARBOSE AND MALTOSE ON THE REACTIVITY OF INDIVIDUAL TRYPTOPHANYL RESIDUES IN GLUCOAMYLASE FROM ASPERGILLUS NIGER
}

\author{
by \\ BIRTE SVENSSON, ANTHONY J. CLARKE") and IB SVENDSEN \\ Department of Chemistry, Carlsberg Laboratory, \\ Gamle Carlsberg Vej 10, DK-2500 Copenhagen Valby \\ "Present address: Department of Chemistry, \\ University of Guelph, Guelph, Ontario, Canada N1G 2W1
}

Keywords: N-bromosuccinimide, peptide fragments, RP-HPLC, oxindolealanine, 2nd derivative UV-spectrophotometry, tyrosine susceptibility, raw starch-binding, thermal stability

Tryptophanyl residues of A. niger glucoamylase G2 (EC 3.2.1.3) involved in substrate and inhibitor binding have been identified following N-bromosuccinimide (NBS) treatment in the presence and absence of protective ligands. Appropriate proteolytic cleavages of the glucoamylase derivatives enabled isolation of individual peptide fragments containing the 15 tryptophan positions and the extent of tryptophan oxidation was measured employing normal and 2 nd derivative UV-spectrophotometry.

Trp-52, $-141,-156,-228,-317$, and -335 remained unoxidized while complete oxidation of Trp-6, -28 , and -466 and partial oxidation of Trp-170 and -178 was observed after NBS-treatment whether ligands were added or not. Trp-212, -417 , and -437 were partially converted in uncomplexed glucoamylase while the presence of either the substrate maltose or the inhibitor acarbose prevented the oxidation of these residues. Trp-120, required for maintaining the active catalytic site, was protected by acarbose only, and its oxidation did not prevent ligand binding. The functional roles of $\operatorname{Trp}-212,-417,-437$, and -120 are discussed.

NBS-treatment of the acarbose-protected large form of glucoamylase, G1, destroyed its unique capacity to adsorb onto starch granules while catalytic activity was preserved towards soluble substrates. This effect could be correlated with the oxidation of Trp-590 and -615 located near the COOH-terminus.

The reactivities, probably reflecting the degree of solvent exposure, were also assessed for individual tyrosyl residues in $G$ ?.

The thermal stability of oxidized, catalytically active G1 and G2 was remarkably low as compared to the unmodified forms.

Abbreviations: $\mathrm{G} 1$ and $\mathrm{G} 2$ designate the larger and the smaller forms of glucoamylase from A. niger $(29,43)$; CM= S-carboxymethyl-; NBS = N-bromosuccinimide; $\mathrm{nW}_{\mathrm{ox}}=$ number $(\mathrm{n})$ of oxidized tryptophanyl residues per enzyme molecule; 2-pe- = 2-pyridylethyl-; RP-HPLC = reversed-phase high performance liquid chromatography; Tris = 2-amino-2(hydroxymethyl)- 1,3-propandiol; * signifies glycosylation. 


\section{INTRODUCTION}

Glucoamylase (1,4- $\alpha$-D-glucan glucohydrolase, EC 3.2.1.3) releases glucose from the nonreducing ends of starch and related substances (32). Two forms of glucoamylase, termed G1 and $\mathrm{G} 2$, are produced by the black mold Aspergillus niger $(20,29)$. The amino acid sequence of the $\mathrm{G} 2$ form is identical to residues 1 through $512(40)$ of the peptide chain of $\mathrm{Gl}$, which is 616 residues long $(5,42)$. This suggested $G 2$ to be generated by limited proteolysis of $\mathrm{G} 1(12,40)$. G1 is functionally distinct from $\mathrm{G} 2$ by its capacity to adsorb onto and to degrade starch granules $(43,45)$. Thus, the COOH-terminal segment of the $\mathrm{Gl}$ is likely to play an important role in the interaction with raw starch.

Fungal glucoamylases possess an extended substrate binding area with six or seven subsites accomodating the glucose residues of linear substrates and the catalytic site located between subsites 1 and $2(13,36)$. Substrate initially binds loosely to subsite 2 via the glucose residue at the non-reducing end, it then shifts to subsite 1 in a unimolecular rearrangement process to form a tight productive complex with concomitant quenching of tryptophan fluorescence and subsequent release of the terminal glucose residue $(13,26,27)$.

In the A. niger glucoamylase-ligand complexes, one and two tryptophanyl residues appear to be in contact with bound maltose and acarbose, respectively (7). The first of these residues, which probably is located in subsite 1 , was protected against NBS-oxidation by a variety of inhibitors and substrates, including soluble starch, whereas only acarbose protected two residues. The derivative having one protected tryptophan retained the ligand binding capacity, although it was catalytically inactive, while the derivative with two tryptophans protected remained active. The second tryptophanyl residue, which presumably is responsible for maintenance of the structural integrity of the active site, has recently been identified as Trp-120 in G2 (8) and is probably located in the fourth subsite $(7,8,35)$.

In the present study the susceptibility of all tryptophanyl residues in glucoamylase G2 to NBS was determined in both the absence and presence of ligands. Three residues, not includ- ing Trp-120, appeared jointly to participate in ligand binding. They may be located in subsite 1 . A study of the NBS-oxidation of Gl was also conducted to determine the role of tryptophanyl residues in raw starch-binding, and it was observed that oxidation significantly reduces the thermal stability of both G1 and G2.

\section{MATERIALS}

Glucoamylase G1 and G2 were purified as previously described from a commercial preparation of A. niger glucoamylase (AMG 200L) which was a gift from Novo Industries, Bagsvaerd, Denmark (43).

Acarbose (a pseudotetrasaccharide and potent inhibitor of glucoamylase (44)) was generously supplied by Drs. E. TRUSCHEIT and D. SCHMIDT (Bayer AG, Wuppertal, F.R.G.). Raw corn starch was a gift of Dr. B.S. ENEvOLDSEN (Department of Brewing Chemistry, Carlsberg Research Laboratory). Reagents, proteolytic enzymes, solvents, and chromatographic gels used for modification and fragmentation of proteins, sequence analysis and isolation of peptides/glycopeptides were obtained from the sources mentioned previously $(7,8,40-42)$.

\section{METHODS}

\subsection{Preparation of oxidized forms of glucoamylase}

G1 and G2 were treated with NBS in the absence and presence of either acarbose $(0.15$ $\mathrm{mM}$ ) or maltose (56 $\mathrm{mM}$ ) as described (7). Ligands and excess reagents were removed by dialysis against $0.1 \mathrm{M}$-sodium acetate $\mathrm{pH} \mathrm{4.3}$; the acarbose-enzyme complex was first dissociated by dialysis against $1.7 \mathrm{M}$-Tris- $\mathrm{HCl} \mathbf{~ p H ~ 7 . 6 . ~ T h e ~}$ enzyme derivatives were subsequently purified by affinity chromatography on acarbose-Sepharose (8). Preparations to be used for the identification of oxidized amino acid residues were finally dialyzed against water and lyophilized, while those designated for investigations of thermostability and raw starch-binding were dialysed against $0.1 \mathrm{M}$-sodium acetate $\mathrm{pH} 4.3$ and 0.1 M-sodium acetate $\mathrm{pH} 3.6$, respectively. These derivatives were either used immediately or stored at $-18^{\circ} \mathrm{C}$. 


\subsection{Preparation and purification of peptide fragments}

NBS-oxidized glucoamylase was reduced and carboxymethylated $(14,43)$ or 2-pyridylethylated $(10,41)$. Portions of 30-100 mg of CM-G2 were digested with trypsin followed by fractionation on Bio-Gel P-100 $(8,41)$. The peptide pools obtained were further purified by affinity chromatography on Con A-Sepharose (41) or by RP-HPLC (8, 22, 40, 41). 2-pe-G2 replaced CM-G2 for preparation of Asn(161)-Arg(194) and Ala(195)-Arg(241) in reasonable yields (41). These fragments were subfragmented with $\alpha$ chymotrypsin and subsequently subjected to RP-HPLC (40). The large, highly glycosylated tryptic fragment T2-1 $(40,41)\left(0.9 \mathrm{mg} \times \mathrm{ml}^{-1}\right)$ was digested with $S$. aureus V8 protease, using a substrate to enzyme mass ratio of $40: 1$ in 0.1 $\mathrm{M}$-ammonium bicarbonate $\mathrm{pH} 7.8$ at room temperature for $3 \mathrm{~h}$, and the resulting fragments $(5 \mathrm{mg})$ were separated by gel filtration on BioGel P-60 $(1.5 \times 90 \mathrm{~cm})$ in $0.2 \mathrm{M}$-ammonium bicarbonate. Tryptic fragments from the $\mathrm{COOH}$-terminal region of G1 have been prepared as earlier published (41). The peptide nomenclature is as reported in refs. (40-42).

\subsection{Raw starch-binding}

The binding of $G 1$ and the derivative $G 1-6 W_{o x}$ to starch granules was measured according to SAHA and UEDA (33). Raw corn starch was washed with $0.1 \mathrm{M}$-sodium acetate $\mathrm{pH} 3.6$ and aliquots $(900 \mu \mathrm{l})$ containing $0.1 \mathrm{~g}$ of starch were added to enzyme solutions $(100 \mu \mathrm{l})$ to give final protein concentrations of $0.02-1.2 \mathrm{mg} \times \mathrm{ml}^{-1}$. After gentle shaking for $20 \mathrm{~min}$ at $4{ }^{\circ} \mathrm{C}$, the mixtures were centrifuged and the fraction of unadsorbed protein was determined from the UV-absorbance of the supernatant at $280 \mathrm{~nm}$.

\subsection{Thermostability}

Aliquots from stock solutions of G1, G2 and the corresponding catalytically active, oxidized forms $(100 \mu \mathrm{l})$, were added to preheated 0.1 M-sodium acetate $\mathrm{pH} 4.3$ (900 $\mu$ l, final protein concentration: $9 \mu \mathrm{M}$ ) and incubated for $5 \mathrm{~min}$ at different temperatures followed by quick freezing in dry-ice/ethanol. Later all samples were thawed, preequilibrated for $5 \mathrm{~min}$ at $25^{\circ} \mathrm{C}$ anc then $30 \mathrm{~mm}$-maltose $(1 \mathrm{ml})$ was added to mea sure the remaining activity (43). The progress 0 inactivation at constant temperatures within the range $50-70{ }^{\circ} \mathrm{C}$ was followed by analysis o enzymic activity in aliquots removed at appro. priate time intervals. The apparent first ordes rate constant, $k$, was determined for the initial part of the inactivation and the activation energy, $E_{a}$, was calculated from the Arrhenius equation, $\mathrm{K}=\operatorname{Aexp}\left(-\mathrm{E}_{\mathrm{a}} / \mathrm{RT}\right)$.

\subsection{UV-Spectrophotometry}

The extent of tryptophan oxidation in isolated tyrosine containing peptides could be determined with good precision from measurement of tryptophan contents by 2 nd derivative spectrophotometry $(8,37)$. In fragments containing tryptophan and/or oxindolealanine but no tyrosine and in 2-pyridylethylated fragments the fraction of oxidized tryptophan, $W_{o x}$, was determined by a modification of the method of SPANDE and WITKOP (38) according to the equation:

$$
W_{\text {ox }}=\frac{E_{\text {unox }}-E_{\text {obs }}}{E_{\text {unox }}} \times 1.31
$$

where $E_{\text {unox }}$ is the absorbance at $280 \mathrm{~nm}$ calculated for the corresponding unoxidized fragment from the concentration (determined by amino acid analysis) using $\varepsilon_{280}=5500 \mathrm{M}^{-1} \times \mathrm{cm}^{-1}$ for a tryptophanyl and $\varepsilon_{280}=1450 \mathrm{M}^{-1} \times \mathrm{cm}^{-1}$ for a tyrosyl residue. $E_{o b s}$ is the actual absorbance of the isolated fragment at $280 \mathrm{~nm}$. The empirical factor 1.31 described by SPANDE and WITKOP (38) corrects for the oxindolealanine absorbance at $280 \mathrm{~nm}$. In cases where tryptophan is absent (demonstrated by 2 nd derivative spectroscopy) oxindolealanine was determined spectrophotometrically employing $\varepsilon_{250}=6600 \mathrm{M}^{-1} \times \mathrm{cm}^{-1}$ (8).

\subsection{Analytical procedures}

Concentrations of $\mathrm{G} 1$ and $\mathrm{G} 2$ were determined spectrophotometrically using $\varepsilon_{280}=1.37$ $\times 10^{5}$ and $1.09 \times 10^{5} \mathrm{M}^{-1} \times \mathrm{cm}^{-1}$, respectively (7). Concentrations of the oxidized forms were determined by amino acid analysis. The enzymic activity was assayed by hydrolysis of maltose ( 15 mM) (43). Amino acid analysis of acid hydro- 
lysates of peptides and protein derivatives was carried out as reported (41-43). $\mathrm{NH}_{2}$-Terminal sequencing in the presence of Polybrene was performed using a Beckman $890 \mathrm{C}$ Sequencer $(15,18)$. The phenylthiohydantoin-amino acids were analyzed by RP-HPLC (39). UV-spectra were recorded using a Cary 219 while a Varian 2200 spectrophotometer was employed for 2 nd derivative UV-spectrophotometry.

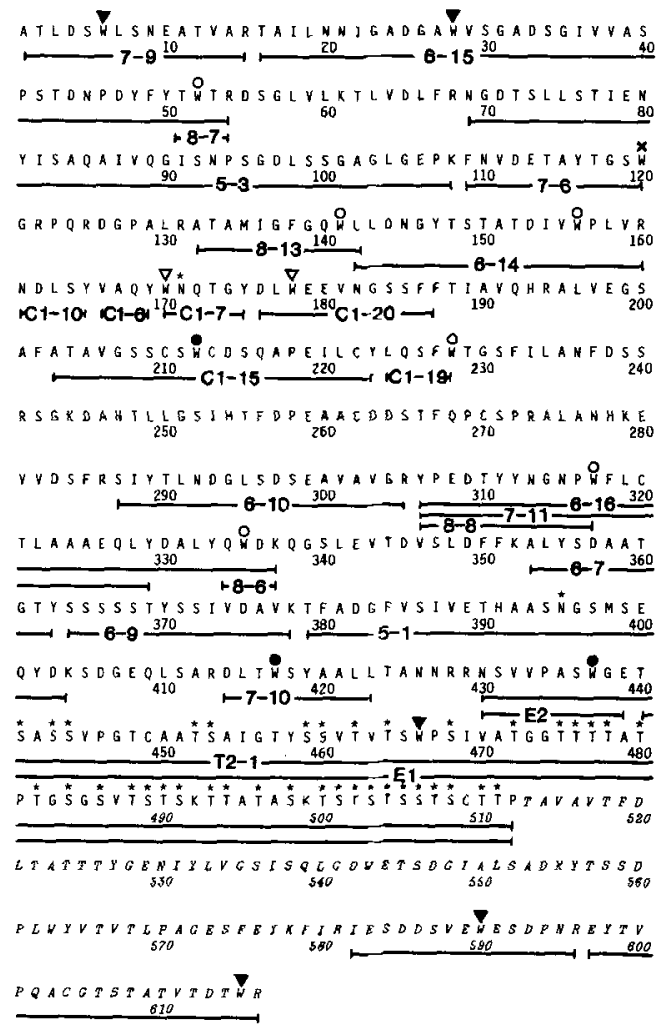

Figure 1. Reactivity of tryptophanyl residues in glucoamylase from $A$. niger. $\nabla$ Indicates residues fully oxidized and $\nabla$ residues partially oxidized irrespective of the presence of ligands, $x$ Indicates the residue protected by acarbose only, residues protected both by maltose and acarbose, and $O$ residues inaccessible to NBS-oxidation. Asterisks designate glycosylated positions. From the $\mathrm{COOH}$-terminal segment specific to $G \perp$ (shown in italics) two tryptic fragments were prepared and purified as described (41). The glucoamylase sequence was reported in refs. 5, 40, and 42 .

\section{RESULTS}

\subsection{Identification of tryptophanyl and oxindolealanyl residues in NBS- treated glucoamylase}

Glucoamylases $\mathrm{G} 1$ and $\mathrm{G} 2$ show very similar behaviour in interactions with inhibitors and soluble substrates $(7,30,43)$. Since peptide fragments were not easily recovered from the region from Leu-521 to Lys-555 which is only present in G1 (see Figure 1) (42), the main study of the tryptophan reactivities was done on the smaller $G 2$ molecule terminated by Pro-512 (40).

The isolated tryptophan containing peptides are indicated in the glucoamylase sequence in Figure 1. Their amino acid compositions, RPHPLC retention times and $\mathrm{NH}_{2}$-terminal sequence analyses are described in Table I. The strategy chosen for polypeptide cleavage ensured that the tryptophan positions were all in separate fragments. The RP-HPLC chromatograms published in ref. 40 were used as guide for isolation of short and medium size tryptic fragments, plus chymotryptic subfragments, which represented the totai of residues I through 429 of G2 (40). The large $\mathrm{COOH}$-terminal fragment, $\mathrm{T} 2-1=\operatorname{Asn}(430)-\operatorname{Pro}(512)$, was purified $(40,41)$ and subsequently digested by $S$. aureus V8 protease to the subfragments Asn(430)Glu(439)(E2) and Thr(440)-Pro(512)(E1), containing Trp-437 and -466 , respectively (Figure 1; Table I).

The oxidized peptides eluted during RPHPLC with practically identical retention times as their tryptophan containing counterparts described elsewhere (40). Nevertheless, quantitative analysis of all tryptophan positions in derivatives of a protein as large as G2 is hardly feasible. Thus, RP-HPLC has the drawback that all peptides are not isolated in similar yields. Moreover, in practice the yields were difficult to estimate for certain $\mathrm{G} 2$ fragments because they, as earlier demonstrated, eluted at more than one position in gel filtration and/or in RP-HPLC (40). Furthermore, the high trypsin:substrate ratio needed for generation of exclusively soluble $G 2$ fragments resulted in further degradation of most of the tryptic fragments comprising the tryptophan positions. Minor deviations also existed between the RP-HPLC patterns of frag- 
ments from oxidized (not shown) and unoxidized G2 (40). Such differences appear to stem from spontaneous cleavage of peptide bonds containing the $\alpha$-carbonyl group of oxindolealanine and from altered protease susceptibilities. Direct sequencing of oxidized $\mathrm{G} 2$ confirmed the first point for positions $6,28,120$, and 466 in $10-30 \%$ of the protein molecules. Only oxindolealanine was found at these four positions (Tables I and II) both by spectrophotometric analysis of isolated tryptic fragments, which corresponded to fragments generated also from unoxidized G2 (40), and indirectly by sequencing following acid-promoted complete cleavage of peptide bonds involving oxindolealanine ( $\mathrm{Ta}$ ble II). In summary, based on the amount of CM- or 2-pe-G2 subjected to tryptic digestion, the $G 2$ tryptophan positions were found in peptide fragments isolated in roughly estimated recoveries of $30-80 \%$. The single exception was Trp-170 in Trp(170)-Tyr(175) (C1-7, Figure 1) which was obtained in only $10 \%$ yield. Substantial release of tryptophan/oxindolealanine probably had taken place from position 170 , since, in accordance with hydrolysis of both peptide bonds in the tripeptide Tyr-Trp-Asn(171) (see Figure 1), Val(166)-Trp(170) was not detected and Asn(171)-Tyr(175) was recovered in a reasonable yield of $40 \%$. In conclusion, we have been able to isolate the 15 tryptophanyl positions and we suggest, in spite of the complications mentioned above, that the contents of oxindolealanine and tryptophan in the analyzed peptides reliably reflect the extent of oxidation for the individual positions in the various derivatives of glucoamylase.

The differing NBS-susceptibility of tryptophans in acarbose-protected $\mathrm{G} 2\left(\mathrm{G} 2-4 \mathrm{~W}_{\mathrm{ox}}\right)$, maltose-protected G2 (G2-5 $W_{\mathrm{ox}}$ ) and unprotected $G 2\left(G 2-6 W_{0 x}\right)$ identify the positions affected by the ligand binding. Earlier results implied that maltose protects a single tryptophanyl residue in A. niger glucoamylases against oxidation (7). In contrast, it is found in the present study that maltose has prevented the partial oxidation observed with uncomplexed G2 at three positions, viz. Trp-212, -417 , and -437 (Table II). Acarbose also protected these three residues and in addition the essential Trp-120 (8). None of the ligands interfered with the oxidation of $\operatorname{Trp}-6,-28,-170,-178$ and -466 . Trp-52, $-141,-156,-228,-317$, and -335 remained unoxidized both in the presence and absence of ligands (Table II). The limited accessibility of Trp-170 and -178 (see Table II) could arise from the proximity of the carbohydrate unit on Asn-171 (41). The reactivity of other residues is probably dependent on the folding of the polypeptide chain. In the presence of 8 M-urea apparently 14 out of the 15 tryptophans in G2 undergo oxidation.

For glucoamylase G2 oxidized under nondenaturing conditions in the absence of ligands $\left(\mathrm{G} 2-6 \mathrm{~W}_{\mathrm{ox}}\right.$, Table II) the fractions of oxindolealanine formed at the 9 susceptible tryptophan positions represent a total of 6 oxindolealanyl residues per molecule, which is in excellent agreement with the extent of oxidation calculated from the UV-spectrum of NBS-treated G2 $(7,38)$. The earlier reported contribution of oxidized tyrosyl residues (see 4.2) to spectral changes (25) was thus insignificant in the case of glucoamylase.

G1 has four more tryptophans than G2, located in the $\mathrm{COOH}$-terminal segment (see Figure 1). NBS-treatment of $\mathrm{Gl}$, in the presence and absence of various protective ligands, resulted in a series of derivatives which contained two more oxindolealanyl residues in comparison to the corresponding derivatives of $\mathrm{G} 2$ (7). Investigations of the tryptic fragments from the $\mathrm{COOH}$-terminal region of oxidized $\mathrm{Gl}$ revealed complete conversion to oxindolealanine at both positions 590 and 615 in acarbose-protected, enzymically active as well as in fully oxidized, inactive G1 (Figure 1 and Table I).

\subsection{Identification of the oxidized tyrosyl residues in NBS-treated glucoamylase}

The tyrosyl content was found by amino acid analysis of oxidized $G 1$ and $G 2$ to be reduced by 4 and by 3 residues, respectively. Apparently this loss of tyrosine was independent of ligands added prior to the NBS-treatment (7) and examination of peptides from the fully oxidized $\mathrm{G} 2$ (Table III) revealed the complete loss of a single specific residue together with minor losses for most of the tyrosyl residues. The tyrosine lost was identified as Tyr-329 by comparison of the 


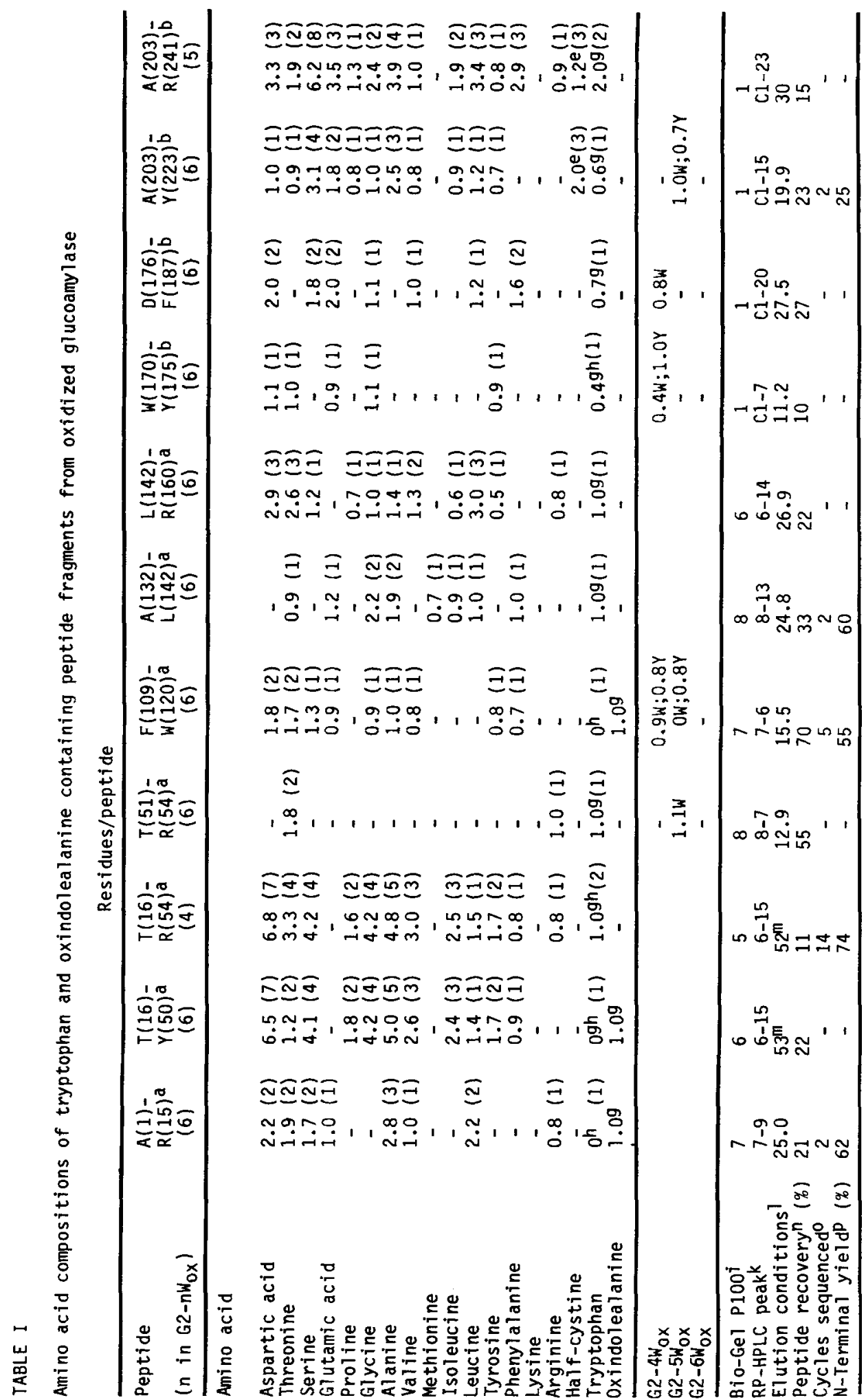




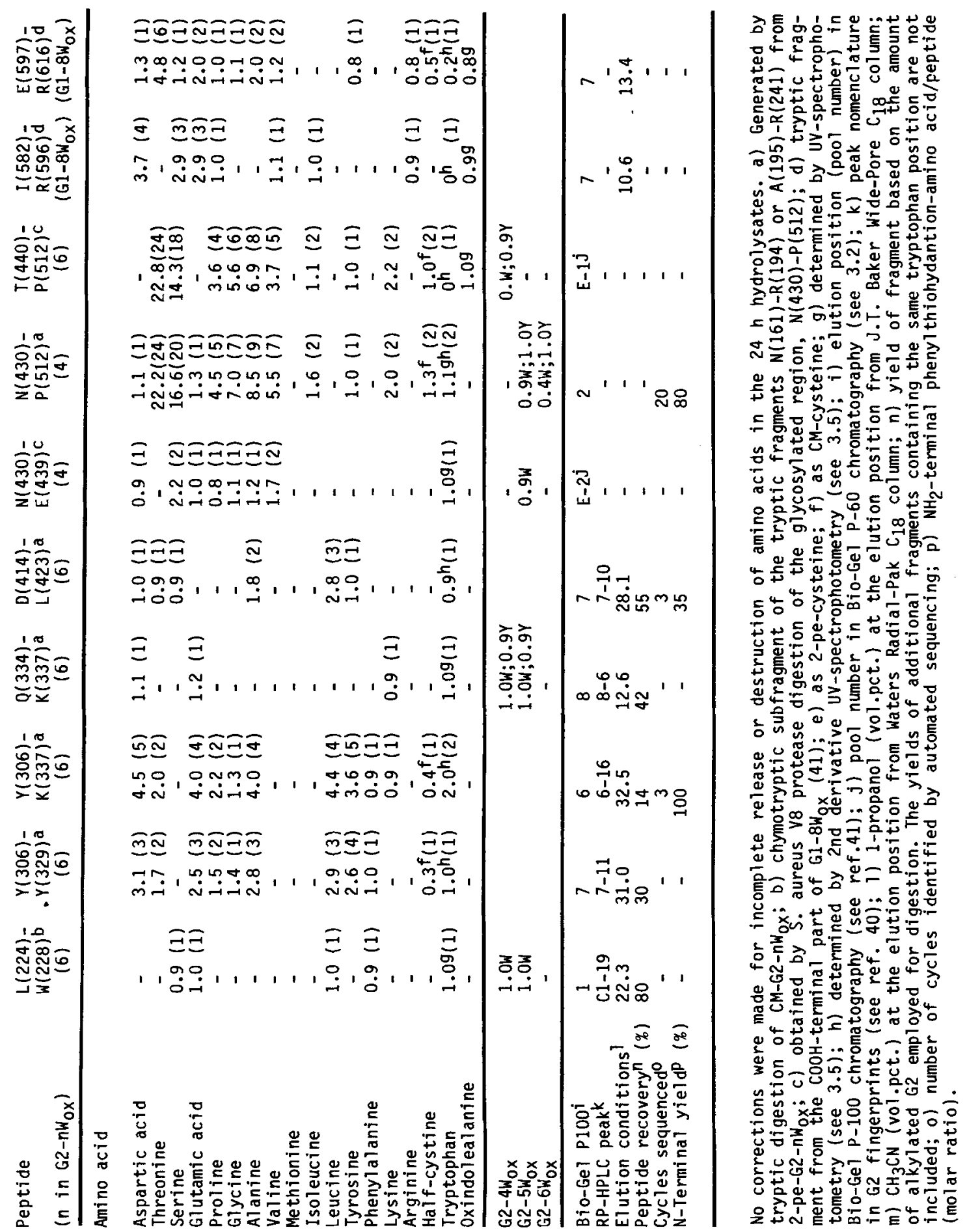


Table II. Effect of acarbose and maltose on the reactivity of tryptophans in G2 to NBS

\begin{tabular}{|c|c|c|c|c|}
\hline \multirow[b]{2}{*}{$\begin{array}{l}\text { Position in } \\
\text { the sequence }\end{array}$} & \multicolumn{3}{|c|}{ Fraction of tryptophan intact } & \multirow[b]{2}{*}{ Experimental evidence } \\
\hline & $\begin{array}{l}G 2-4 W_{o x} \\
\text { (acarbose) }\end{array}$ & $\begin{array}{l}G 2-5 W_{o x} \\
\text { (maltose) }\end{array}$ & $\begin{array}{l}\mathrm{G} 2-6 W_{\mathrm{ox}} \\
\text { (no ligand) }\end{array}$ & \\
\hline 6 & 0 & (0) & 0 & $4 W_{o x}(a, b) ; 6 W_{o x}(a, b, c)$ \\
\hline 28 & 0 & $(0)$ & 0 & $4 W_{o x}(a, b, d) ; 6 W_{o x}(b, c)$ \\
\hline 52 & 1.0 & 1.0 & 1.0 & $4 W_{o x}(d, e) ; 5 W_{o x}$ and $6 W_{o x}(c)$ \\
\hline 120 & 1.0 & 0 & 0 & $4 \mathrm{~W}_{o x}$ and $5 \mathrm{~W}_{\mathrm{ox}}(\mathrm{c}, \mathrm{d}) ; 6 \mathrm{~W}_{\mathrm{ox}}(\mathrm{b}, \mathrm{c}, \mathrm{d})$ \\
\hline 141 & $(1.0)$ & $(1.0)$ & 1.0 & $6 \mathrm{~W}_{\mathrm{ox}}(\mathrm{c})$ \\
\hline 156 & $(1.0)$ & $(1.0)$ & 1.0 & $6 W_{o x}(c)$ \\
\hline 170 & 0.4 & $(0.4)$ & 0.4 & $4 W_{o x}$ and $6 W_{o x}(c)$ \\
\hline 178 & 0.8 & $(-)$ & 0.7 & $4 W_{o x}$ and $6 W_{o x}(c)$ \\
\hline 212 & $(1.0)$ & 1.0 & 0.6 & $5 \mathrm{~W}_{\mathrm{ox}}(\mathrm{c}) ; 6 \mathrm{~W}_{\mathrm{ox}}(\mathrm{c}, \mathrm{d})$ \\
\hline 228 & 1.0 & 1.0 & 1.0 & $4 W_{o x}, 5 W_{o x}$ and $6 W_{o x}(c)$ \\
\hline 317 & $(1.0)$ & $(1.0)$ & 1.0 & $6 \mathrm{~W}_{\mathrm{ox}}(\mathrm{c}, \mathrm{d})$ \\
\hline 335 & $(1.0)$ & $(1.0)$ & 1.0 & $6 W_{o x}(c)$ \\
\hline 417 & 1.0 & 1.0 & 0.9 & $4 W_{o x}, 5 W_{o x}$ and $6 W_{o x}(c, d)$ \\
\hline 437 & 1.0 & 0.9 & 0.4 & $4 W_{o x}, 5 W_{o x}$ and $6 W_{o x}(a, c, d)$ \\
\hline 466 & 0 & 0 & 0 & $4 W_{o x}(b, d) ; 5 W_{o x}(c, d) ; 6 W_{o x}(b, c, d)$ \\
\hline
\end{tabular}

The values in parentheses were deduced from results obtained for $\mathrm{G} 2$ oxidized to a lower and higher degree. Peptides comprising the positions are further described in Table I and indicated in the sequence shown in Figure 1.

a) Automated sequencing of the position in question (see Table I); b) cleavage of the peptide bond containing the $\alpha$-carbonyl group of oxindolealanine as detected by direct sequencing of the $\mathrm{G} 2$ derivative after redissolution in $70 \%$ trifluoroacetic acid; c) UV-spectrophotometry (see Table I); d) 2nd derivative UV-spectrophotometry (see Table I); e) $\mathrm{COOH}$-terminal sequencing utilizing carboxypeptidases $\mathrm{B}$ and $\mathrm{Y}$ in combination (42).

Table III. Recovery of tyrosine in peptide fragments from NBS-oxidized G2

\begin{tabular}{lcl}
\hline Fragment & $\begin{array}{l}\text { Tyrosine(s) } \\
\text { in the sequence }\end{array}$ & $\begin{array}{l}\text { Tyrosine(s) } \\
\text { recovered }\end{array}$ \\
\hline Thr(16)-Tyr(50) & 2 & 1.9 \\
Asn(69)-Lys(108) & 1 & 1.0 \\
Phe(109)-Trp(120) & 1 & 0.8 \\
Leu(142)-Arg(160) & 1 & 0.5 \\
Asn(161)-Tyr(165) & 1 & 0.5 \\
Val(166)-Tyr(169) & 1 & 0.9 \\
Asn(171)-Tyr(175) & 1 & 0.9 \\
Ala(203)-Tyr(223) & 1 & 0.8 \\
Ser(287)-Arg(305) & 1 & 1.0 \\
Tyr(306)-Trp(317) & 3 & 2.6 \\
Tyr(306)-Tyr(329) & 4 & 2.7 \\
Tyr(306)-Lys(337) & 5 & 3.6 \\
Ala(353)-Tyr(363) & 2 & 1.7 \\
Ser(364)-Lys(378) & 1 & 1.0 \\
Thr(379)-Lys(404) & 1 & 0.9 \\
Asp(414)-Leu(423) & 1 & 0.7 \\
Asn(430)-Pro(512) & 1 & 1.0 \\
\hline
\end{tabular}

The fragments have been prepared from $\mathrm{G} 2-6 \mathrm{~W}_{\mathrm{ox}}$ and the tyrosine contents were determined by amino acid analysis. The fragments are indicated in Figure 1. tyrosine contents in the peptides $\operatorname{Tyr}(306)$ $\operatorname{Tyr}(317)$, Tyr(306)-Tyr(329), and Tyr(306)Lys(337) (Table III).

\subsection{Effect of NBS-treatment on raw starch- adsorption}

When G1 was modified by NBS in the presence of acarbose the resulting derivative had 6 oxindolealanyl residues and retained approx. $80 \%$ of the original catalytic activity towards maltose (7) but the affinity for raw starch was lost. Thus less than $0.05 \mathrm{mg}$ of $\mathrm{G} 1-6 \mathrm{~W}_{\mathrm{ox}}$ adsorbed, in contrast to $0.8 \mathrm{mg}$ of $\mathrm{G} 1$, onto $0.1 \mathrm{~g}$ of starch (Figure 2). Provided the tryptophans in the acarbose complexes of G1 and G2 have similar susceptibility to NBS the lack of raw starch-binding capacity can be correlated with oxidation of two additional residues, Trp-590 and -615 (see 4.1), near the COOH-terminus of G1 (Figure 1). 


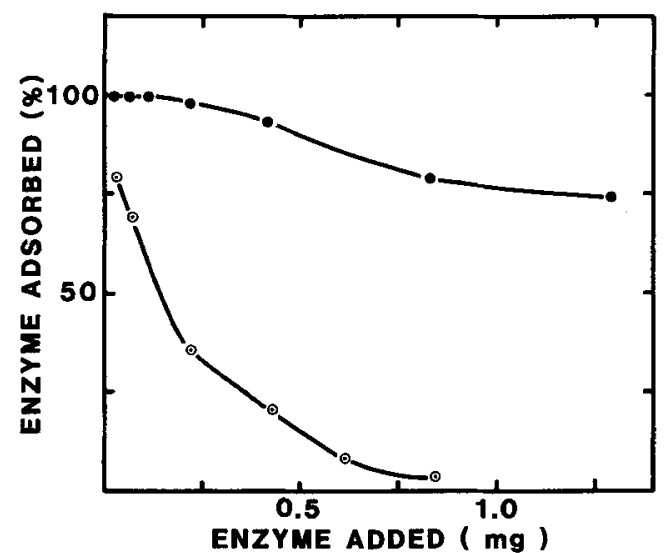

Figure 2. Raw starch-adsorption of glucoamylase G1 $(--)$ and oxidized, catalytically active G1-6W $(-\odot-)$. The amount of protein bound was calculated by subtraction of the unadsorbed protein from the total amount added to raw starch suspended in $0.1 \mathrm{M}$-sodium acetate $\mathrm{pH}$ 3.6.

\subsection{Thermal stability of NBS-treated G1 and G2}

The catalytically active G1-6 $W_{\text {ox }}$ and G2$4 \mathrm{~W}_{\text {ox }}$ were both inactivated considerably faster than $G 1$ and $G 2$ when incubated at temperatures in the range $50-70{ }^{\circ} \mathrm{C}$ (Figure 3). The apparent first order rate constants and the calculated activation energies for the denaturation are compared for the unmodified enzymes and their active, oxidized forms (Table IV). The oxidation was found, in spite of retained catalytic activity (7), to reduce the thermal stability of the glucoamylases drastically.

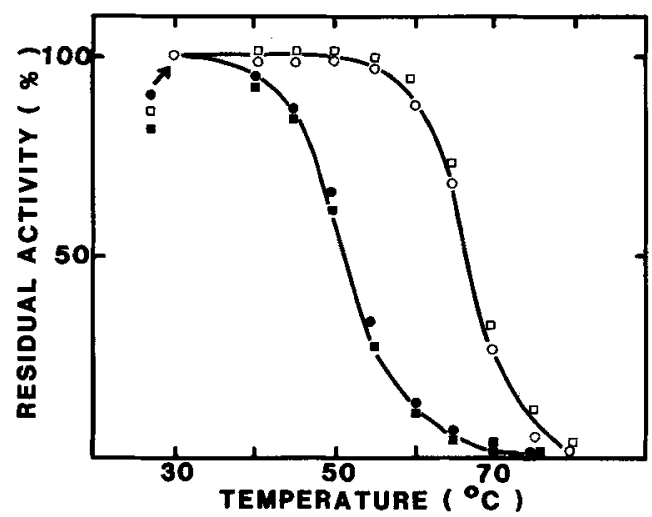

Figure 3. Thermostability of $\mathrm{G} 1(O)$ and $\mathrm{G} 2(\square)$ and the corresponding catalytically active derivatives, G1$6 \mathrm{~W}_{\mathrm{ox}}(\bullet)$ and $\mathrm{G} 2-4 \mathrm{~W}_{\mathrm{ox}}(\boldsymbol{\nabla})$. The enzymes $(9 \mu \mathrm{M})$ were incubated at varying temperatures in $0.1 \mathrm{M}$-sodium acetate $\mathrm{pH} 4.3$ for $5 \mathrm{~min}$ and the residual activity determined using maltose as substrate.

\section{DISCUSSION}

Previously Trp- 120 in glucoamylase G2 from A. niger was shown to be an essential residue, responsible for maintaining the functional integrity of the active site, although its oxidation did not hinder ligand binding to the enzyme ( 7 , 8). Both these experiments and independent studies on the identical enzyme from $A$. awamori $(24,35)$ indicated the essential tryptophan to be located at some distance from the catalytic site, possibly in the fourth substrate binding subsite. Figure 4 shows the structural model of the active site of glucoamylase introduced by

Table IV, Effect of NBS-oxidation on the thermostability of glucoamylase

\begin{tabular}{lll}
\hline Enzyme & $\begin{array}{l}\text { Rate of inactivation, } \mathrm{k} \\
\left(10^{3} \times \mathrm{min}^{-1}\right)\end{array}$ & $\begin{array}{l}\text { Activation energy, } \mathrm{E}_{\mathrm{a}} \\
\left(\mathrm{kJ} \times \mathrm{mol}^{-1}\right)\end{array}$ \\
\hline $\mathrm{G} 1-6 \mathrm{~W}_{\mathrm{ox}}$ & 260 & 110 \\
$\mathrm{G} 2-4 \mathrm{~W}_{\mathrm{ox}}$ & 690 & 90 \\
$\mathrm{G} 1$ & 6.7 & 280 \\
$\mathrm{G} 2$ & 5.7 & 260 \\
\hline
\end{tabular}

The apparent first order rate constant for inactivation, $\mathrm{k}$, was calculated from the loss of enzymic activity at $55^{\circ} \mathrm{C}$ during the initial 5-10 min of incubation at a protein concentration of $12 \mu \mathrm{M}$ in $0.1 \mathrm{M}$-sodium acetate $\mathrm{pH} 4.3$. The activation energy, $E_{2}$, was calculated from the Arrhenius equation using k-values determined at $50,55,60,65$, and $70{ }^{\circ} \mathrm{C}$. 


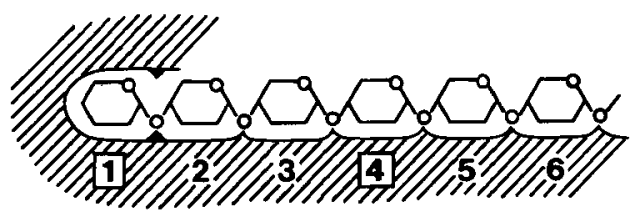

Figure 4. Tentative model of the active site of glucoamylase. The wedges denote the catalytic site; a productive malto-oligosaccharide enzyme-complex is indicated $(13,27)$. Three and one tryptophanyl residues are suggested to be located in or near subsites 1 and 4 , respectively (the present work and ref. 8).

Hiromi and his colleagues $(13,27)$. Trp-120 belongs to a region of the molecule which shows sequence homology with a glucoamylase from Saccharomyces diastaticus (46). In addition, Trp-52, -170, and -178 of glucoamylase from A. niger are conserved in the corresponding yeast enzyme $(41,46)$, which points to them as possible candidates in the search for the tryptophanyl residue tentatively associated with subsite 1 and protected by a variety of substrates and inhibitors $(7,13)$. The results of the present study, however, indicated none of them to be in this site since, whether ligands were present or not, Trp-52 was inaccessible to NBS-oxidation while Trp-170 (adjacent to the glycosylated Asn-171 and therefore unlikely to be located in subsite 1 of an exoglucanase) and -178 were converted to oxindolealanine in $60 \%$ and $30 \%$ yield, respectively. In contrast, three other residues, identified as Trp-212, -417 , and -437 , were protected from NBS-oxidation both by maltose and by acarbose. In preparations of fully oxidized $G 2$, which are devoid of ligand binding ability, these three positions are modified to an extent of approx. $40 \%, 10 \%$, and $60 \%$ respectively. Thus, their side chains would not be freely accessible, reflecting perhaps that this part of the substrate binding site forms the end of a pocket or crevice. Since the substrate maltose binds in a productive mode, i.e. in subsites 1 and 2 according to the model in Figure 4, it is likely that Trp-212, -417, and -437 are located in close proximity to one or both of these subsites. Oxidation experiments in the presence of glucose and gluconolactone are consistent with this proposal. Thus glucose, a competitive inhibitor which binds in subsite 2 (27), does not provide any protection from NBS-oxidation whereas gluconolactone, considered to be a transition state analogue located in subsite 1 (13), affords protection and secures an enzyme derivative that, while catalytically inactive, is still able to bind substrates and inhibitors (7).

If $\operatorname{Trp}-212,-417$, and -437 are clustered in subsite 1 it is conceivable that oxidation of one or two side chains sterically hinders the oxidation of the remaining one(s), perhaps through conformational changes. That the formation of oxindolealanine can cause local conformational changes in a substrate binding cleft has been observed with hen-egg white lysozyme. In this case the specific oxidation of Trp- 62 induced a shift of the three-dimensional structure which blocked subsite $C$ of the active site cleft such that productive binding is prevented (4). Oxidation of Trp-108 in lysozyme similarly induced a conformational change near the catalytic residue Glu-35 $(3,11)$.

While the current proposals are consistent with the various observations recorded in this and other studies $(7,13,16)$, they do not eliminate the possibility of an alternative explanation. Indeed, the porcine pancreatic $\alpha$-amylase is known to have an additional sugar binding site located on the surface outside of the active site area (28). Similarly, a second substrate binding region was implicated from studies of barley malt $\alpha$-amylase subsites in amylose hydrolysis (21). Thus, the three protected glucoamylase G2 residues, Trp-212, -417 and -437 , perhaps belong to different ligand binding sites rather than being located in the active site region. Finally, we cannot exclude the possibility that the three tryptophanyl residues, or one or two of them, are also required for catalysis to occur, since derivatives have not been obtained in which Trp-212, -417 , and -437 are oxidized while the essential Trp- 120 remained intact.

Only the larger form of A. niger glucoamylase, G1, adsorbs onto and digests raw starch $(43,45)$. This unique capacity is presumably associated with a second binding site on the surface of the enzyme distinct from the active site and probably involves the $\mathrm{COOH}$-terminal segment specific for $\mathrm{G} 1$. When $\mathrm{G} 1$ was modified by NBS 
in the presence of acarbose the raw starch-binding ability was lost in an otherwise catalytically active derivative. Out of the four tryptophans in the $\mathrm{COOH}$-terminal segment we have shown that the two nearest to the $\mathrm{COOH}$-terminus, i.e. Trp-590 and -615 , were converted to oxindolealanine. A connection between structural elements from this region in $\mathrm{G} 1$ and the affinity for raw starch is therefore strongly suggested and the isolation from A. niger culture liquid of a raw starch-binding inhibitory factor which has a size and amino acid composition similar to the $\mathrm{COOH}$-terminal segment of Gl (34) lends support to this proposal. Further studies are needed to elucidate whether other parts of the G1 molecule participate in the raw starch-binding.

The oxidations caused a destabilization of glucoamylase in the temperature range $50-70$ ${ }^{\circ} \mathrm{C}$. Similarly, NBS-oxidized semi-alkaline proteinase from Aspergillus melleus showed decreased thermal stability (19). A detailed characterization of the inactivated glucoamylases was not attempted in the present study. However, it was found that cleavage of peptide bonds containing the $\alpha$-carbonyl group of oxindolealanine residues occurred to some degree in the derivatives. Perhaps elevated temperatures, like acidic conditions, facilitated scission of these labile peptide bonds with subsequent unfolding of the protein. Thermal stability of proteins has also been attributed to the presence of salt bridges between charged amino acid residues as well as to hydrophobic interactions among non-polar residues and it has recently been shown that aromatic-aromatic interactions play a major role in the stabilization of protein tertiary structure $(6,31)$. Furthermore, tryptophanyl residues are knowp to initiate and stabilize $\alpha$-helices (1). It is not surprising, therefore, if oxidation of the very hydrophobic tryptophan (9) to the more polar oxindolealanine caused disruption of stabilizing structural elements. In summary, mild oxidation of glucoamylase in the presence of acarbose provides a less thermostable, catalytically active form, but whether the main cause of the inactivation was the chemical modification of certain residues or the peptide backbone cleavage, preceded perhaps by a scrambling of the tertiary structure or by aggregation $(2,17)$, cannot be decided at the moment.
The present work suggests that $\operatorname{Trp}-212,-417$, and -437 in the glucoamylase from $A$. niger are jointly associated with ligand binding in subsite 1 while Trp-120, also present in glucoamylase from $S$. diastaticus (46) and probably present in Taka-amylase A from A. oryzae $(8,23)$, belongs to the fourth substrate binding subsite (8).

\section{ACKNOWLEDGEMENTS}

We are grateful to Professor MARTin OTTESEN for stimulating and helpful discussions and for revision of the manuscript. Mss EDITH Fløistrup, Sidsel Ehlers, and BirgitTe MARKUSSEN are thanked for expert technical assistance with preparation and characterization of the enzyme derivatives. Mss BoDIL Corneliussen, Lone Sørensen, and Pia BREDDAM are acknowledged for amino acid analysis and peptide sequencing. Drs E. TRUSCHEIT and D. SCHMIDT, Bayer AG, are thanked for the gift of acarbose and Professor DITER V. WeTtSTEIN, Department of Physiology, Carlsberg Laboratory for the use of the Varian 2200 recording spectrophotometer.

\section{REFERENCES}

1. Adler, A. J., N. J. Greenfield \& G. D. Fasman: Circular dichroism and optical rotatory dispersion of proteins and polypeptides. Meth. Enzymol. 27, 675-735 (1973)

2. BALDWIN, R. L.: Intermediates in protein folding reactions and the mechanism of protein folding. Ann. Rev. Biochem. 44, 453-475 (1975)

3. Beddell, C. R., C. C. F. Blake \& S. J. OAtley: An $\mathrm{X}$-ray study of the structure and binding properties of iodine-inactivated lysozyme. J. Mol. Biol. 97, 643-654 (1975)

4. Blake, C. C. F., R. Cassels, C. M. Dobson, F. M. Poulsen, R. J.P. Williams \& K. S. Wilson: Structure and binding properties of hen lysozyme modified at tryptophan 62. J. Mol. Biol. 147, 73-95 (1981)

5. BoEl, E., I. HJort, B. SvensSON, F. NorRis, K. E. NorRIS \& N. P. FIIL: Glucoamylases G1 and G2 from Aspergillus niger are synthesized from two different but closely related mRNAs. EMBO J. 3, 1097-1102 (1984)

6. Burley, S. K. \& G. A. Petsko: Aromatic-aromatic interaction: A mechanism of protein structure-stabilization. Science 229, 23-28 (1985) 
7. Clarke, A. J. \& B. Svensson: The role of tryptophanyl residues in the function of Aspergillus niger glucoamylase G1 and G2. Carlsberg Res. Commun. 49, 111-122 (1984)

8. Clarke, A. J. \& B. SvensSON: Identification of an essential tryptophanyl residue in the primary structure of glucoamylase G2 from Aspergillus niger. Carlsberg Res. Commun. 49, 559-566 (1984)

9. FAUCHERE, J. L.: How hydrophobic is tryptophan? Trends Biochem. Sci. 10, 268 (1985)

10. Friedman, M., J. C. Zahniey \& J. R. Wagner: Estimation of the disulfide content of trypsin inhibitors as S- $\beta$-(2-pyridylethyl)-L-cysteine. Anal. Biochem. 106, 27-34 (1980)

11. Hartdegen, F. J. \& J. A. Rupley: Oxidation of lysozyme by iodine: Identification of oxindolealanine 108. J. Mol. Biol. 80, 649-656 (1973)

12. HAYASHIDA, S. \& E. YoshiNO: Formation of active derivatives of glucoamylase I during the digestion with fungal acid protease and $\alpha$-mannosidase. Agric. Biol. Chem. 42, 927-933 (1978)

13. Hiromi, K., M. OHNishi \& A. Tanaka: Subsite structure and ligand binding mechanism of glucoamylase. Mol. Cell. Biochem. 51, 79-95 (1983)

14. HIRS, C. H. W.:Reduction and S-carboxymethylation of proteins. Meth. Enzymol. 25, 199-203 (1972)

15. Johansen, J. T., C. Overballe-Petersen, B. Martin, V. Hasemann \& I. SVendsen: The complete amino acid sequence of copper, zinc superoxide dismutase from Saccharomyces cerevisiae. Carlsberg Res. Commun. 44, 201-217 (1979)

16. Jolley. M. E. \& C. J. GraY: Tryptophanyl and carboxylic acid residues in the active center of glucoamylase I from Aspergillus niger. Carbohydr. Res. 49, 361-370 (1976)

17. JOLY, M.: A physicochemical approach to the denaturation of proteins. Academic Press, New York (1965)

18. KLAPPER, D. G., C. E. Wilde III \& J. D. Capra: Automated amino acid sequence of small peptides utilizing Polybrene. Anal. Biochem. 85, 126-131 (1978)

19. Kobayashi, S., T. Tazawa, M. Sasaki, S. Kiryu\& M. Suglura: Chemical modification of tryptophan and histidine residues in semi-alkaline proteinase from Aspergillus melleus. Chem. Pharm. Bull. 32, 3111-3117 (1984)

20. LINEBACK,D.R. \& L. A. AIRA: Structural characterization of the two forms of glucoamylase from Aspergillus niger. Cereal Chem. 49, 283-296 (1972)

21. MacGregor, E. A. \& A. W. MACGregor: The action of cereal $a$-amylases on solubilized starch and cereal starch granules. In: New Approaches to Research on Cereal Carbohydrates (ed. R. D. Hill \& L. Munck, Elsevier, Amsterdam, 1985) 149-160

22. MahoneY, W. C. \& M. A. Hermodson: Separation of large denatured peptides by reverse phase high performance liquid chromatography. Trifluoroacetic acid as a peptide solvent. J. Biol. Chem. 255, $11199-11203$ (1980)

23. Matsuura, Y., M. Kusunoki, W. Harada \& M. KAKUDO: Structure and possible catalytic residues of Taka-amylase A. J. Biochem. 95, 697-702 (1984)

24. Nunberg, J. -H., J. H. Meade, G. Cole, F. C. Lawyer, P. MCCAGe, V. Schweickart, R. Tal, V. P. Wittman, J. E. Flatgaard \& M. A. InNis: Molecular cloning and characterization of the glucoamylase gene of Aspergillus awamori. Mol. Cell. Biol. 4, 2306-2315 (1984)

25. OhNishl, M., T. Kawagishi, T. AbE\& K. Hiromi: Stopped-flow studies on the chemical modification with $\mathrm{N}$-bromosuccinimide of model compounds of tryptophan residues. J. Biochem. 87, 273-279 (1980)

26. OHNishi, M., M. Taniguchi \& K. HiRomi: Kinetic discrimination of tryptophan residues of glucoamylase from Rhizopus niveus by fast chemical modification with $\mathrm{N}$-bromosuccinimide. Biochim. Biophys. Acta 744, 64-70 (1983)

27. OhNishi, M., H. Kegal \& K. Hiromi: Studies on the subsite structure of amylases. I. Interaction of glucoamylase with substrate and analogues studied by difference spectrophotometry. J. Biochem. 77, 695-703 (1975)

28. Payan, F., R. Haser, M. Pierrot, M. Frey \& J. P. ASTIER: The three-dimensional structure of $\alpha$ amylase from porcine pancreas at $5 \dot{A}$ resolution. The active site location. Acta Cryst. B36, 416-421 (1980)

29. Pazur, J. H. \& T. ANDO: The action of an amyloglucosidase of Aspergillus niger on starch and malto-oligosaccharides. J. Biol. Chem. 234, 19661970 (1959)

30. Pazur, J. H., H. R. Knull \& A. Cepure: Glycoenzymes: structure and properties of the two forms of glucoamylase from Aspergillus niger. Carbohydr. Res. 20, 83.96 (1971)

31. Ponnuswamy,P.K., R. Muthusamy \& P. MonaVALAN: Amino acid composition and thermal stability of proteins. Int. J. Biological Macromolecules 4, 186-190 (1982)

32. REILly, P. J.: Starch hydrolysis with soluble and immobilized glucoamylase. Appl. Biochem. Bioeng. 2, 185-206 (1979)

33. SAHA, B. C. \& S. UEDA: Raw starch adsorption, elution and digestion behaviour of glucoamylase of 
Rhizopus niveus. J. Ferment. Technol. 61, 67-72 (1983)

34. SAHA, B. C. \& S. Ueda: Production and characteristics of inhibitory factor of raw starch digestion from Aspergillus niger. Appl. Microbiol. Biotechnol. 19, 341-346 (1984)

35. SAVEL'EV, A.N.\& L.M. FirSov: Effect of modification of some amino acid radicals on enzymatic activity of glucoamylase from Aspergillus awamori. Biokhimiya 48, 1311-1318 (1983)

36. Savel'ev, A. N., V. R. Sergeev \& L. M. Firsov: Study of the active site of glucoamylase from Aspergillus awamori. Biokhimiya 47, 390-397 (1982)

37. Servillo, L., G. Colonna, C. Balestrieri, R. RAGONE\& G. IRACE: Simultaneous determination of tyrosine and tryptophan residues in proteins by second-derivative spectroscopy. Anal. Biochem. 126, 251-257 (1982)

38. SPANDE, T. F. \& WitKoP, B.: Determination of the tryptophan content of proteins with N-bromosuccinimide. Meth. Enzymol. XI, 498-506 (1967)

39. SVEndSEn, I., B. Martin \& I. Jonassen: Characteristics of hiproly barley III. Amino acid sequences of two lysine-rich proteins. Carlsberg Res. Commun. 45, 79-85 (1980)

Accepted by H. KLENOW
40. Svensson, B., K. Larsen \& A. Gunnarsson: Characterization of a glucoamylase G2 from Aspergillus niger. Eur. J. Biochem. 154, 497-502 (1985)

41. SVensson, B., K. Larsen \& I. Svendsen: Amino acid sequence of tryptic fragments of glucoamylase G1 from Aspergillus niger. Carlsberg Res. Commun. 48, 517-527 (1983)

42. SVensson, B., K. LarSen, I. SVEndSen \& E. Boel: The complete amino acid sequence of the glycoprotein, glucoamylase G1 from Aspergillus niger. Carlsberg Res. Commun. 48, 529-544 (1983)

43. Svensson, B., T. G. Pedersen, I. Svendsen, T. SAKAI \& M. OTTESEN: Characterization of two forms of glucoamylase from Aspergillus niger. Carlsberg Res. Commun. 47, 55-69 (1982)

44. Truscheit, E., W. Frommer. B. Junge. L. MÚlLER, D. D. SCHMIDT \& W. WINGENDER: Chemie und Biochemie mikrobieller $\alpha$-Glucosidaseninhibitoren. Angew. Chem. 93, 738-755 (1981)

45. UEdA, S.: Fungal glucoamylases and raw starch digestion. Trends Biochem. Sci. 6, 89-90 (1981)

46. Yamashita, I., K. Suzuki \& S. FukUI: Nucleotide sequence of the extracellular glucoamylase gene STA1 in the yeast Saccharomyces diastaticus. J. Bacteriol. 161, 567-573 (1985) 